\title{
Empreendedorismo e Transferência Tecnológica: uma análise da atuação das incubadoras de empresas da Amazônia
}

\section{Entrepreneurship and Technological Transfer: an analysis of the activity of Amazon business incubators}

\author{
Márcio Luís Góes de Oliveira ${ }^{1}$ \\ Cirilo Simões Filho ${ }^{2}$ \\ Cláudio Márcio Campos de Mendonça ${ }^{3}$ \\ Walter Teixeira Lima Júnior ${ }^{4}$ \\ ${ }^{1}$ Instituto Federal de Educação, Ciência e Tecnologia do Amapá, Macapá, AP, Brasil \\ ${ }^{2}$ Centro de Ensino Superior do Amapá, Macapá, AP, Brasil \\ ${ }^{3}$ Universidade Federal do Amapá, Macapá, AP, Brasil \\ ${ }^{4}$ Universidade Federal de São Paulo, São Paulo, SP, Brasil
}

\begin{abstract}
Resumo
Transferência Tecnológica (TT) é um processo de troca de conhecimentos e habilidades tecnológicas entre organizações. Há diversos instrumentos para a viabilização da TT, entre elas as incubadoras de empresas, organismos que têm como missão o fortalecimento da cultura empreendedora, associadas à política de inovação das ICTs. Assim, este artigo objetivou analisar como as incubadoras de empresas da Amazônia atuam para apoiar a transferência das tecnologias dos empreendimentos incubados. A abordagem ao problema foi qualitativa e quantitativa, com estudo de casos. Utilizou-se como referência as incubadoras membros da Associação Nacional de Entidades Promotoras de Empreendimentos Inovadores (ANPROTEC). Os sites institucionais das incubadoras pouco têm detalhado como funcionam os processos de apoio à transferência tecnológica e também a descrição dos instrumentos de negociação, valoração e prontidão tecnológica (TRL). Um ponto relevante refere-se ao uso de parcerias no processo de TT como solução para limitações das ICTs amazônicas.
\end{abstract}

Palavras-chave: Transferência de Tecnologia. Incubadoras de Empresas. Amazônia.

\begin{abstract}
Technology transfer (TT) is a process of knowledge exchange and technological skills between firms. There are several instruments for enabling TT, including business incubators, organizations whose mission is to strengthen the entrepreneurial culture, associated with the innovation policy of the STI's. This paper aimed to analyze how the incubators of Amazonian companies act to support the process of transfer of technologies developed by the enterprises they incubate. The approach was qualitative and quantitative way, with study of cases. Incubators members of the National Association of Innovative Enterprises Promoting Entities (ANPROTEC) were used as a reference.The institutional websites of incubators have little detailed how the processes of support for technology transfer work and the description of trading, valuation and technological readiness (TRL). A point identified was the use of partnerships in the TT process as a solution to the lack of human and financial resources of Amazonian STI's.
\end{abstract}

Keywords: Technology Transfer. Business Incubators. Amazon.

Área Tecnológica: Propriedade Intelectual. Inovação e Desenvolvimento. 


\section{Introdução}

O Desenvolvimento socioeconômico necessita da ação organizada de diversos atores. No caso da atuação inventiva do ser humano, por exemplo, para que esta possa beneficiar efetivamente a sociedade, o ato criativo deve romper com o "lugar comum". Para tanto, é necessário que o produto da criação humana consiga alcançar as "prateleiras" às quais a população tem acesso, influenciando no dia a dia das pessoas e proporcionando melhor qualidade de vida, ganho de tempo, economicidade etc.

Para tal, a simbiose entre empresas de base tecnológica e transferência de tecnologia vem ganhando cada vez mais espaço nas ações estratégicas que visam ao desenvolvimento científico, tecnológico e socioeconômico dos países. Segundo Iacono e Nagano (2014), infere-se as empresas de base tecnológica como empreendimentos do século XXI e alavancas do desenvolvimento, tanto científico, quanto social e econômico. Daí depreender-se a importância de organismos como as incubadoras de empresas, que, para a Associação Nacional Promotora de Empreendimentos Inovadores - Anprotec (2012), estão entre os principais instrumentos de transferência tecnológica, sendo habitats que objetivam a consolidação de empreendimentos vocacionados para a inovação.

Assim, o presente estudo terá as incubadoras de empresas de base tecnológica (IEBTs) como agentes a serem observados, focando, porém, especificamente na atuação destas no que tange ao processo de estímulo à transferência das tecnologias (TT) desenvolvidas pelos empreendimentos por elas apoiados. Tal interesse vem em face do que se observa do exposto por Medeiros (2000), quando afirma que a própria criação das incubadoras de empresas na década de 1980 visara a criação de ambientes que facilitassem o processo de transferência de tecnologia.

Como recorte, esta pesquisa analisará especificamente as incubadoras de empresas da Amazônia Legal, um complexo correspondente a $61 \%$ do território nacional, composto pelos estados do Acre, Amapá, Amazonas, Pará, Rondônia, Roraima, Tocantins, Mato Grosso e região ocidental do Maranhão (IBGE, 2014) e conhecida mundialmente por ser o maior sistema de biodiversidade do planeta, além de possuir grande conhecimento tradicional associado, o que faz com que a região amazônica caracterize-se como um ecossistema regional de inovação que possui na sociobiodiversidade local um grande ativo bioindustrial.

Porém, a Amazônia ainda é uma fronteira geopolítica carente no que pese a questões como infraestrutura (viária, industrial, tecnológica, etc.), baixo número de pesquisadores (mestres e doutores), entre outros pontos que fazem com que a região ainda seja um "vazio" quando se fala em desenvolvimento científico e tecnológico. Dadas tais especificidades regionais, é que este artigo objetivou analisar como as incubadoras de empresas da Amazônia atuam para apoiar o processo de transferência das tecnologias dos empreendimentos incubados. Busca-se, assim, compreender como estas incubadoras vêm atuando enquanto instrumento do ecossistema amazônico de inovação que viabiliza a TT dos produtos e serviços do ambiente universitário para o setor produtivo.

Surge, então, o conceito de transferência de tecnologia (TT), que para Kelli et al. (2014) é a troca de conhecimentos e habilidades tecnológicas entre duas organizações, podendo ser entre uma Instituição Científica e Tecnológica (ICT) e uma empresa, entre ICTs e até de empresa para empresa. 
Há, ainda, diversos entendimentos com pontos de vistas convergentes e outros divergentes sobre este tema. A Association of University Technology Managers, por exemplo, entende a TT como um processo de transferência de descobertas científicas de uma organização para outra com a finalidade comercial (AUTM, 2013). Em contraponto, Bozeman (2000) afirma que focar apenas em produto não é suficiente para o entendimento da TT, tendo em vista que não são apenas produtos que são transferidos, mas também conhecimentos quanto à utilização destes.

No processo de transferência tecnológica, uma das questões relevantes é quanto a importância da comunicação da tecnologia e dos conhecimentos passíveis de transferência. Lee et al. (2010) entendem que vários fatores são importantes em um processo de TT, como o relacionamento comprador-fornecedor e a gestão do conhecimento, principalmente no que diz respeito a equipamentos de alta tecnologia; e Lee e Win (2004) entendem que os mecanismos de TT de maior relevância econômica seriam: Intercâmbios acadêmicos, conferências, publicações; b) Consultorias e Prestação de serviços; c) Licenciamento; d) Programas de intercâmbio; e) Incubadoras ou Parques tecnológicos f) Spin-off Acadêmico/Tecnológico e g) Dua - Use Technology. A Anprotec (2012) corrobora com o conceito de Lee e Win (2004) por também entender as incubadoras de empresas como instrumentos de transferência tecnológica, bem como a National Business Incubation Association - NBIA (2008), que enxerga a incubadora como uma sistemática fundamental de apoio a novos empreendimentos.

Mas na prática, quais ações as incubadoras realizam para a TT? Segundo Closs e Ferreira (2012), a transferência de informações através de treinamentos, consultorias, da comunicação tecnológica e da criação de empresas startups estaria entre as ações aplicáveis às incubadoras de empresas para o apoio à transferência do conhecimento e das tecnologias. Costa e Torkomian (2008) entendem ainda que a formação de spin-offs acadêmicos seria uma eficiente alternativa de transferência para a sociedade do conhecimento gerado no ambiente das universidades.

Gomes e Atrasas (2005) afirmam, porém, existirem alguns fatores críticos para o êxito no processo de transferência tecnológica, como: o fator humano, enquanto detentor e/ou receptor da tecnologia; diferenças de expectativas entre as partes, principalmente com relação à aspectos como tempo e sigilo; maturidade da tecnologia passível de transferência e mudanças de estratégias das organizações.

\section{Metodologia}

A abordagem ao problema se deu de maneira qualitativa e quantitativa, com a realização de estudo de casos (múltiplos casos), caracterizado por Gil (2008) como a investigação de um ou alguns objetos da pesquisa, de forma que possibilite sua compreensão por inteiro.

Já quanto ao caráter do estudo, este é do tipo descritivo, buscando, como afirma Almeida (2012) a exposição das características de determinada população, sendo que a padronização quanto ao uso de técnicas de coletas de dados estão entre as principais características desta tipologia.

Para o início dos estudos, efetuou-se levantamento bibliográfico a fim de alcançar a apropriação conceitual sobre a atuação das incubadoras de empresas quanto ao processo de transferência de tecnologias dos empreendimentos incubados. 
Em seguida, para a realização do estudo utilizou-se como referência as incubadoras constantes na lista de membros da Associação Nacional de Entidades Promotoras de Empreendimentos Inovadores (ANPROTEC) e da Rede Amazônica em Prol do Empreendedorismo e da Inovação (RAMI), lançando-se mão para a coleta de dados de formulário (Google forms) com perguntas semiestruturadas com questões abertas encaminhadas por e-mail aos gestores das incubadoras. Realizaram-se ainda perguntas por telefone, procurando assim refinar o presente estudo.

$\mathrm{Na}$ etapa posterior, fez-se a análise documental nos sites das incubadoras de empresas amazônicas que responderam ao questionário, procurando regulamentações, informativos, processos mapeados e demais documentos que pudessem nortear o entendimento de como as incubadoras atuavam para apoiar transferência das tecnologias desenvolvidas pelos empreendimentos incubados.

Segue a Figura 1 com o mapa de identificação das incubadoras estudadas.

Figura 1 - Mapa de Identificação das Incubadoras Pesquisadas

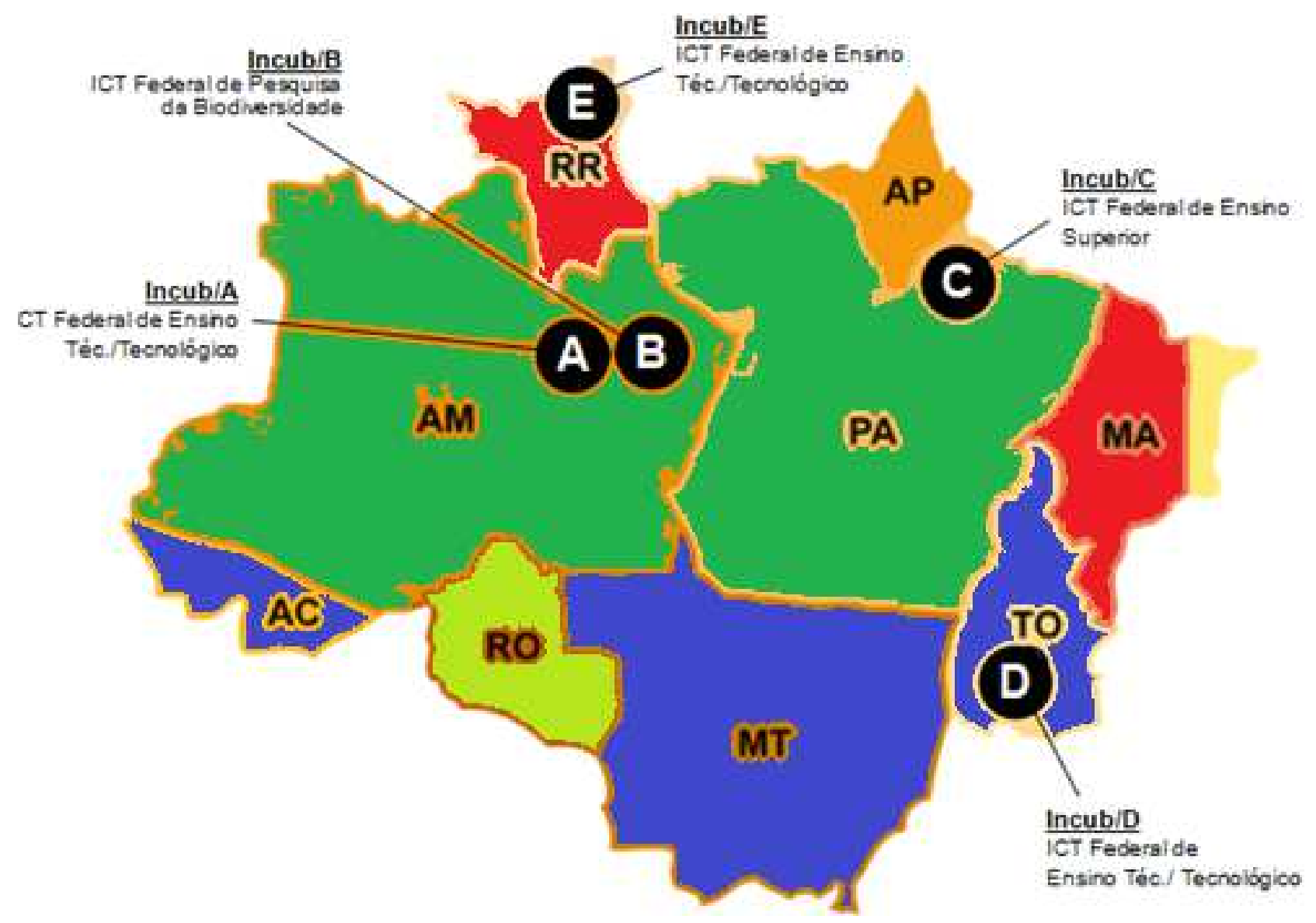

Fonte: Dados da Pesquisa (2019)

Foram contatadas 23 incubadoras, das quais obteve-se o total de 05 respondentes. A pesquisa foi realizada no período de 15 de junho a 15 de julho de 2019, e no que tange à divulgação deste estudo optou-se por preservar a identidade tanto das incubadoras, bem como dos gestores entrevistados aplicando-se a codificação: Incubadora "A", Incubadora "B", Incubadora "C", Incubadora "D" e Incubadora "E". 


\section{Análise e Interpretação dos Dados}

\subsection{Da Análise dos Sites, Normativos e Processos}

Como consta na descrição metodológica, foi realizada análise nos sítios de internet das incubadoras que responderam às perguntas encaminhadas aos gestores, além de normativos, processos e demais documentos relativos ao estímulo à transferência tecnológica por parte dos empreendimentos apoiados.

\subsection{Itens de Maior Incidência nos Sites das Incubadoras}

Segue a Figura 2 através da utilização de nuvens de palavras ${ }^{1}$ com a descrição dos termos mais utilizados nos sites das incubadoras de empresas da Amazônia. Objetiva-se, com esta descrição indicar quais os termos de maior frequência nos links dedicados aos serviços prestados pelas incubadoras da região.

Figura 2 - Nuvens das palavras mais frequentes nos sites das incubadoras da Amazônia

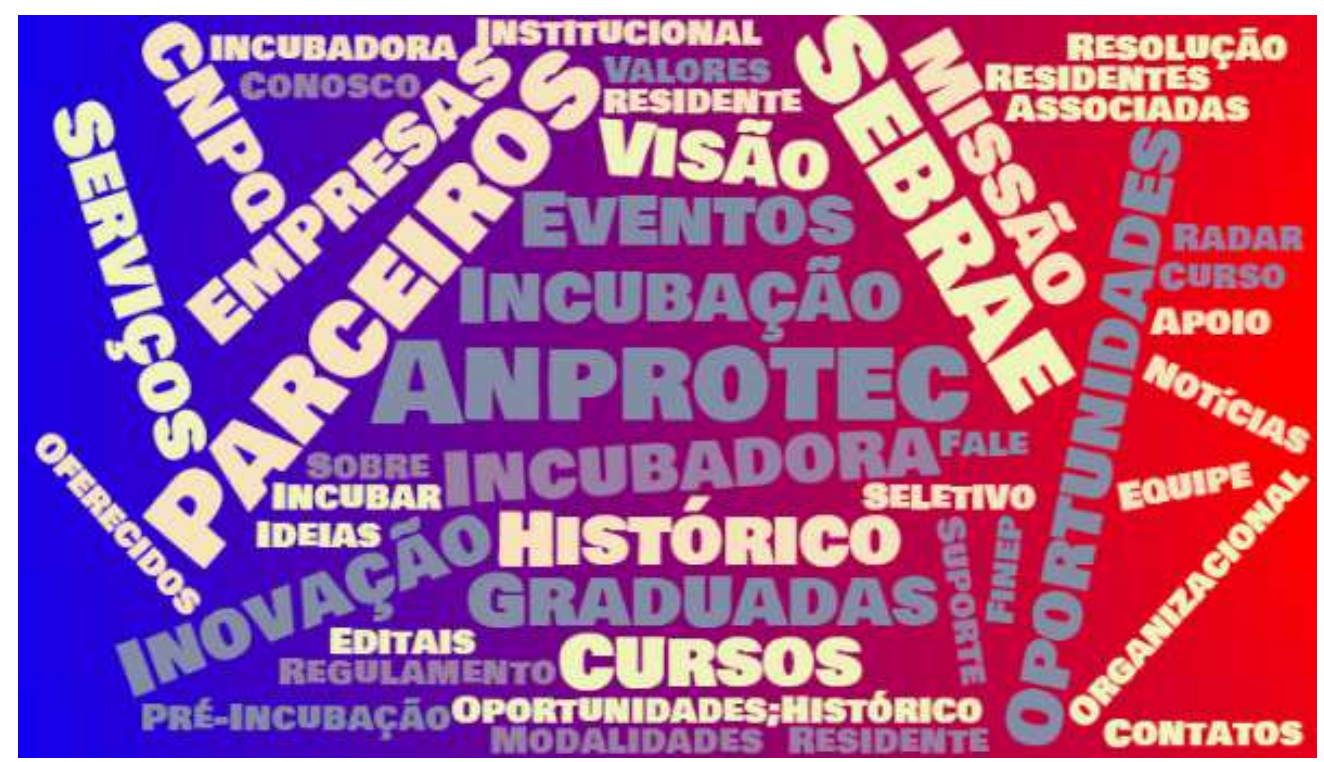

Fonte: Dados da Pesquisa (2019)

Verifica-se que as nomenclaturas de maior frequência indicam que as parcerias institucionais das incubadoras são os nomes mais citados. Além disso, pode-se verificar que o termo "transferência de tecnologia" não consta no rol de expressões.

\subsection{Análise da Incubadora " $\mathrm{A}$ "}

A incubadora "A" é a organização de maior tempo de fundação, estando em atividade desde 2003. É vinculada à uma instituição científica e tecnológica (ICT) federal, sendo da tipologia mista $^{2}$, e possui atualmente 02 empreendimentos incubados. De todos os sites de incubadoras

1 Nuvens de palavras (NP) são imagens usualmente apresentadas como ilustração à leitura superficial do senso comum. O tamanho de cada palavra indica sua frequência (SURVEYGIZMO, 2012).

2 Incubadoras que apoiam tanto empresas de base tecnológica quanto tradicionais (ANPROTEC, 2012). 
analisadas é aquele em que mais facilmente se encontram dados sobre as ações e características da incubadora.

Já no que tange ao registro de como a incubadora atua no processo de transferência tecnológica, não há descrição em sua regulamentação (Resolução n. 65/CONSUP). Na entrevista realizada a gestora da incubadora realizou a seguinte afirmação: "a incubadora " $\mathrm{A}$ " já é em si própria um mecanismo de transferência de tecnologia e o Núcleo de Inovação Tecnológica (NIT) é quem possui a atribuição de gerir este processo na instituição".

Em comparação com outros estudos, Monteiro (2005), através de pesquisas realizadas junto ao Parque Tecnológico da Paraíba (PaqTcPB), afirma que as boas práticas de comunicação são ferramentas poderosas de projeção das entidades no que diz respeito à responsabilidade social e na divulgação de geração de negócios para as empresas incubadas.

Em outro estudo, que realizou a análise do impacto da comunicação entre as incubadoras associadas à Rede Amazônica de Incubadoras de Empresas (RAMI), constatou-se que uma das maiores dificuldades encontradas era justamente o estabelecimento de um canal sistemático e seguro de comunicação para o compartilhamento de competências e conhecimentos gerados na incubadora (MACEDO; BASSALO, 2005).

\subsection{Análise da Incubadora "B"}

A incubadora "B" é vinculada a uma instituição científica e tecnológica (ICT) com expertise na realização de pesquisas voltadas ao desenvolvimento sustentável dos recursos naturais amazônicos através do estudo da biodiversidade regional, possuindo atualmente 03 empresas incubadas.

Observou-se que no site institucional da incubadora há o link com o Regimento Interno, com a descrição "en passant" da estrutura organizacional e as atribuições da unidade responsável pela política de inovação da ICT: "Seção XVII - Da Coordenação de Extensão Tecnológica e Inovação" XVI - criar e incubar projetos de base tecnológica ou relacionados à inovação”. Porém a referida incubadora não possui a descrição dos mecanismos de transferência de tecnologia.

Quando da realização da entrevista telefônica com a gestão da incubadora foi feita seguinte afirmação: "com relação à transferência de tecnologia a incubadora "B" não possui ainda a descrição, o fluxo do processo de incubação e de TT". Assim, toma-se como base o estudo de Gomes e Atrasas (2005) que citam entre os fatores críticos de sucesso ao processo de TT na ausência de uma sistemática que confira profissionalismo e comprometimento, além do papel fundamental do fator humano tanto enquanto fornecedor como receptor das tecnologias.

Outro fator detectado é que a incubadora é vinculada ao que na instituição seria o NIT. Sendo assim, incubadora e NIT estão inscritos na mesma unidade organizacional, como assim foi descrito pela gestora da incubadora: "A Incubadora de empresas faz parte da Coordenação de Extensão Tecnológica e Inovação (COETI) que é o "NIT" da nossa instituição".

\subsection{Análise da Incubadora "C"}

Fundada em 2009 e localizada no Estado do Pará, a incubadora "C" está vinculada a uma ICT federal de ensino superior, sendo que atualmente possui 10 iniciativas de base tecnológica 
incubadas, além caracterizar-se por ter as estratégias de inovação integradas a uma mesma unidade estratégica - uma agência de inovação.

Quanto à análise do portal dedicado à agência de inovação, onde a incubadora está inserida, verificou-se que há links dedicados à: prestação de consultorias tecnológicas; propriedade intelectual (PI) e sobre a coordenadoria de empreendedorismo a quem a incubadora encontra-se vinculada.

Uma interessante descoberta, foi o fato de que a incubadora " $\mathrm{C}$ " utiliza de parceria com uma agência de inovação do sudeste do país (Agência de Inovação da UFRJ) no apoio às atividades de Transferência tecnológica, como descrito na declaração do gestor a incubadora realizada por telefone: "O parceiro que apoia a Incubadora no processo de transferência de tecnologia é a Agência de Inovação da UFRJ". Tal constatação pode indicar uma evolução quanto às articulações de parcerias estratégicas em TT na região, tendo em vista verificar-se que em estudo realizado por Teixeira e Castro (2015) sobre as incubadoras da Amazônia, constatou-se que as incubadoras analisadas não possuíam parcerias relevantes com universidade $e$ institutos de pesquisa, entendendo-se ser um fator que dificultava o desenvolvimento de pesquisas aplicadas na região.

Apesar de não possuir links dedicados aos processos de transferência tecnológica, há de se ressaltar que a incubadora "C" possui um espaço em seu site dedicado à vitrine tecnológica, onde são divulgados resumos das tecnologias desenvolvidas pela universidade e que, diferentemente das demais incubadoras analisadas, trata inclusive (mesmo sem muitos detalhes) da análise da maturidade das tecnologias (Technology Readiness Level - TRL ${ }^{3}$ ) desenvolvidas pela instituição.

Segue a Figura 3 com a demonstração do quadro de maturidade tecnológica (TRL) descrita no site agência de inovação da qual a incubadora "C" faz parte.

Figura 3 - Demonstração do quadro de TRL da incubadora "C"

Os produtos e processos expostos na Vitrine Tecnológica encontram-se em desenvolvimento. Estão categorizados em uma escala niveis de maturidade tecnológica (Technology Readiness Level -TRL) entre 1 a 9, conforme a representação abaixo.

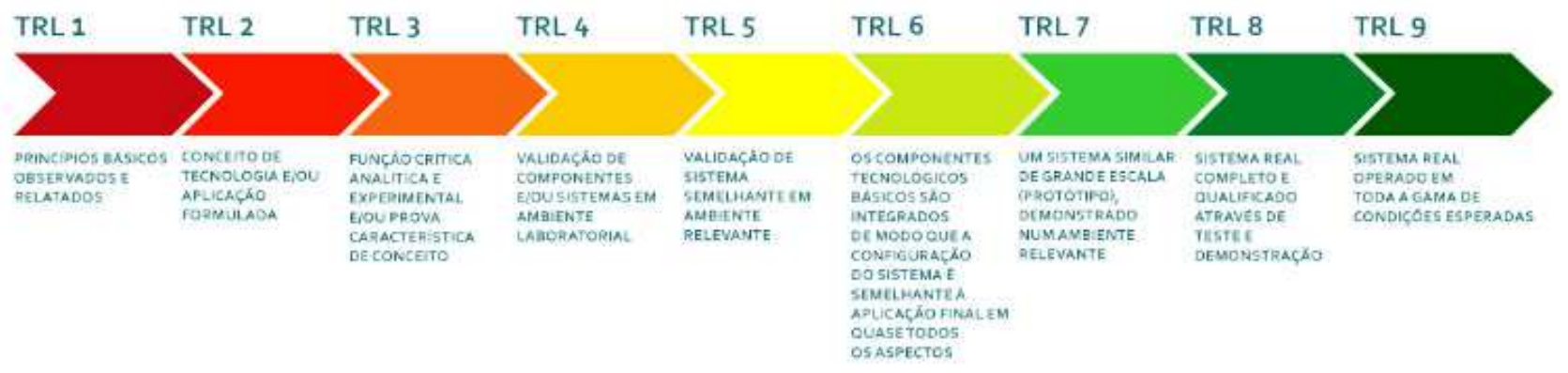

Fonte: Site da Agência de Inovação/Incubadora "C"

\subsection{Análise da Incubadora " $\mathrm{D}$ "}

Trata-se de uma incubadora recente (2016), vinculada a uma instituição federal de ensino técnico e tecnológico localizada no estado do Tocantins, tendo atualmente dois empreendimen-

$3 \mathrm{O}$ termo TRL teve origem em diversos estudos realizados nos departamentos de defesa dos Estados Unidos, Reino Unido, Canadá e Austrália. A NASA foi pioneira na obrigatoriedade de tal mensuração em seus projetos, o que foi seguido por outras agências espaciais (LARGENT, 2003). 
tos incubados e com a missão de atender tanto empreendimentos de base tecnológica quanto de cunho social.

No que concerne à análise do site da instituição, verificou-se que há claramente a descrição da regulamentação (Resolução n. 49/2016/CONSUP), sendo que em nenhum item é tratado como a incubadora atuaria para a comunicação tecnológica de itens passíveis de serem transferidos à sociedade através dos resultados de produtos e serviços desenvolvidos por iniciativas incubadas.

Da análise do site institucional realiza-se a comparação com estudos de Lave et al. (2010), que indicaram que entre os fatores críticos para o sucesso das incubadoras da Amazônia as quais analisaram, estava a eficiente divulgação das ações e estratégias das incubadoras. Em outro estudo, e também no mesmo sentido, Gardim (2011) ressalta a importância dos portais como ferramenta da gestão do conhecimento, que permitem a uma organização gerenciar seus ativos intangíveis e transformá-los em fontes de valor e resultados.

Outra questão registrada, é que, assim como a incubadora " $B$ ", a incubadora " $D$ " é vinculada ao Núcleo de Inovação Tecnológica (NIT), sendo então, que a política de gestão da inovação e promoção do empreendedorismo possui a mesma unidade como responsável.

\subsection{Análise da Incubadora "E"}

A incubadora mais recente entre todas as em estudo (fundada em 2018) é vinculada à uma ICT federal de ensino técnico e tecnológico e localizada no Estado de Roraima. Programada para entrar efetivamente em funcionamento somente no final de 2019, a Incubadora "E" não possui um site ou link dedicado exclusivamente a ela. No entanto, é a que mais cita em seus normativos a transferência tecnológica, como consta no inciso V, a saber: "Capítulo III - Da Finalidade e Objetivos - V - colaborar para o desenvolvimento local e regional, incentivando o empreendedorismo e a inovação, com vistas às criações intelectuais, suas proteções e transferência de tecnologia".

Contudo não constam na regulamentação e nem no site fluxos ou congêneres que indiquem os passos a serem seguidos no processo de TT. Quando da entrevista, o gestor da incubadora forneceu a seguinte declaração: "A nossa Incubadora iniciará suas atividades no último trimestre deste ano. Nossa previsão é iniciar as atividades com o processo de incubação de 10 empresas".

\subsection{Da Caracterização das Incubadoras Respondentes}

Além da análise nos sites e documentos, a pesquisa também coletou dados através de envio de questionários. Às incubadoras que responderam aos questionários entrou-se em contato para a realização de entrevistas, sendo os resultados descritos nos quadros a seguir.

\subsection{Atuação das Incubadoras para o Estímulo à Transferência Tecnológica (TT)}

Foi enviado questionário e realizadas entrevistas com a incubadoras que responderam aos questionários procurando compreender as estratégias utilizadas por elas para apoiar a transferência tecnológica por parte dos empreendimentos em processo de incubação. Assim, 
apresenta-se o Quadro 1 com a seguinte pergunta: Como a sua incubadora atua para apoiar a transferência de produtos e serviços para o mercado?

Quadro 1 - Atuação das Incubadoras para a realização da TT

\section{COMO A SUA INCUBADORA ATUA PARA APOIAR A TT?}

\begin{tabular}{|c|c|}
\hline 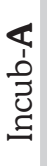 & $\begin{array}{l}\text { "A incubadora "A" já é um mecanismo de TT. Portanto, os produtos desenvolvidos para a empresa } \\
\text { em pré incubação, sob demanda, no laboratório e com apoio de pesquisadores e alunos bolsistas são } \\
\text { comercializados após conclusão da pesquisa e observando o tempo de prateleira, pela empresa, já } \\
\text { incubada, gerando a transferência de tecnologia. O mesmo acontece com serviço gerado de spin-off". }\end{array}$ \\
\hline 舟 & $\begin{array}{l}\text { "A Incubadora de empresas faz parte da Coordenação de Extensão Tecnológica e } \\
\text { Inovação (COETI) que é o "NIT" da nossa instituição. Então essa coordenação é } \\
\text { responsável totalmente pela parte de transferência do que a gente produz". }\end{array}$ \\
\hline 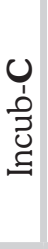 & $\begin{array}{l}\text { "A Incubadora não atua diretamente realizando 'a transferência de produtos e serviços } \\
\text { para o mercado'. Esta é uma tarefa da startup residente. Atuamos indiretamente apoiando } \\
\text { as nossas startups através da Assessoria de Marketing, Assessoria de Imprensa, Assessoria } \\
\text { de Programação Visual, Encontros de Capacitação Decolar, Mentoria especializada, e } \\
\text { Acompanhamento periódico. Eventualmente, de acordo com a disponibilidade de recursos, } \\
\text { também contratamos consultores externos para Assessoria Jurídica, Contábil e Financeira". }\end{array}$ \\
\hline 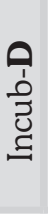 & $\begin{array}{l}\text { "Em nossa instituição quem trata da TT é a Diretoria de Inovação e Empreendedorismo, na } \\
\text { qual há um setor de Propriedade Intelectual e TT. São } 2 \text { pessoas com conhecimento na área } \\
\text { de legislação que atuam. A procuradoria é sim consultada para que tudo ande conforme a } \\
\text { legislação permite. Existe, sim, a necessidade de contratar serviços externos em especial na } \\
\text { área de valoração da tecnologia, mas efetivamente a nossa instituição ainda não fez TT". }\end{array}$ \\
\hline بـ & $\begin{array}{l}\text { "A incumbência total é do NIT da instituição. Ainda estamos criando os regimentos } \\
\text { da incubadora, mas ao meu ver a parte de transferência continuará a ser totalmente } \\
\text { responsabilidade do NIT, cabendo pra incubadora apenas o apoio ao negócio". }\end{array}$ \\
\hline
\end{tabular}

Fonte: Pesquisas dos autores deste artigo

Dado o exposto, no Quadro 1 pôde-se observar que as incubadoras em questão trabalham pouco o processo de comunicação tecnológica, sendo que na totalidade destas a incumbência da articulação da aquisição de possíveis compradores das tecnologias desenvolvidas pelos empreendimentos incubados é do NIT. Entende-se, porém que as incubadoras, em sendo mecanismos de TT, deveriam também participar mais ativamente do processo. Aponta-se, desta forma, o que expõem Lee et al. (2010) quando afirmam a importância da comunicação da tecnologia e/ou conhecimento passíveis de transferência, sendo o processo pelo qual um fornecedor comunica e transmite a tecnologia através da relação comprador-fornecedor e da gestão do conhecimento.

Em outro estudo de caracterização das incubadoras de base tecnológica da Amazônia, realizado por Paskinn et al. (2015), verificou-se que o marketing e a exploração de ferramentas virtuais enquanto vitrines de portfólio das empresas incubadas constava como um dos pontos em que as incubadoras da Amazônia deixavam a desejar, o que se confirma, pois, também com o presente estudo.

\subsection{Fatores Críticos para a Transferência das Tecnologias}

Segue o Quadro 2, em que os gestores das incubadoras analisadas responderam ao seguinte questionamento: Atualmente quais são os principais fatores críticos para o processo de transferências das tecnologias desenvolvidas pelas empresas incubadas em sua instituição? 
Quadro 2 - Fatores críticos para a Transferência Tecnológica dos Empreendimentos Incubados

\begin{tabular}{|l} 
Quais os entraves para a TT de produtos/serviços das Empresas Incubadas? \\
"A falta de cultura empreendedora da instituição, onde a incubadora pode contar com poucos \\
pesquisadores para esse fim. Há muitos colegas docentes que ainda não se sentem partícipes do \\
processo de apoio ao desenvolvimento do empreendedorismo e inovação aqui na instituição".
\end{tabular}

Fonte: Dados da Pesquisa dos autores deste artigo

Apesar de, nas questões anteriores, apresentarem que as principais ações quanto as estratégias de transferência de tecnologia estarem sob a égide dos Núcleos de inovação tecnológica (NITs), até mesmo em virtude da legislação vigente (BRASIL, 2016), observa-se, porém, que os gestores das incubadoras citaram alguns entraves para a realização da transferência das tecnologias de empreendimentos em incubação.

Tal fato pode ser explicado pois, como afirma Lee e Win (2004), as incubadoras por si só já são instrumentos de transferência tecnológica. Expõe-se, ainda, o que afirma Lee et al. (2010), quando ressaltam a importância de um bom relacionamento comprador-fornecedor e da gestão do conhecimento, sendo essas questões a célula mater da atuação das incubadoras.

O disposto no Quadro 2 vem ao encontro do resultado da pesquisa de Oliveira e Mendonça (2018), quando da caracterização do suporte oferecido por parte das incubadoras amazônicas aos empreendimentos incubados. Naquele estudo, a carência de pessoal qualificado e com dedicação exclusiva às atividades da incubadora, a necessidade de maior participação do quadro dos docentes-pesquisadores, as dificuldades de comunicação da incubadora para com a comunidade acadêmica e externa e a incipiência quanto a articulação para a prospecção de parceiros foram questões apontadas pelos gestores das incubadoras.

Para a viabilização da transferência de produtos e serviços para o mercado, há a necessidade de que se averigue se estes estão suficientemente maduros, prontos para a concorrência "extramuros" da incubadora. Assim trata a Association of University Technology Managers (AUTM, 2013), ao afirmar que TT é um processo de transferência de descobertas científicas de uma organização para outra com finalidade comercial. 
Segue o Quadro 3, com as respostas ao seguinte questionamento: Como a incubadora verifica que o produto/serviço já está maduro para ser transferido para o setor produtivo? Há alguma metodologia?

Quadro 3 - Análise sobre a preparação do produto para o Mercado

\begin{tabular}{|c|c|}
\hline \multicolumn{2}{|r|}{ Como a Incubadora analisa se o produto está pronto para o mercado? } \\
\hline 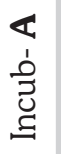 & $\begin{array}{l}\text { "O pesquisador é quem apresenta o parecer final. Antes de iniciar a pesquisa é necessário verificar a } \\
\text { viabilidade do produto ou serviço para não ser desenvolvido um produto sem necessidade de mercado". }\end{array}$ \\
\hline 艄 & $\begin{array}{l}\text { "Não há metodologia desenvolvida para essa atividade. No entanto, nada impede que o } \\
\text { produto/serviço seja transferido. Vai depender muito do grau de inovação do produto, da } \\
\text { maturidade da empresa e da equipe de pesquisadores e colaboradores da instituição". }\end{array}$ \\
\hline 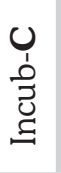 & $\begin{array}{l}\text { "A Incubadora utiliza-se da metodologia Lean StartUp para apoiar suas empresas residentes na } \\
\text { modelagem do negócio, validação do MVP, e posteriormente no processo de vendas. Além disso } \\
\text { realizamos reuniões de monitoramento das empresas residentes de forma periódica, a fim de verificar o } \\
\text { grau de maturidade da startup nas áreas chave mercado, gestão, capital, tecnologia, e empreendedor". }\end{array}$ \\
\hline 是 & $\begin{array}{l}\text { "Não temos estabelecida uma metodologia. Quando da responsa da consulta pública prevista para daqui } \\
30 \text { dias, provavelmente iniciaremos os trabalhos de construção de manuais de operação e regulamentos". }\end{array}$ \\
\hline 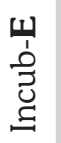 & $\begin{array}{l}\text { "Aceitação do mercado. Procura por empresas. Não há uma metodologia pronta para isso. Talvez, quando } \\
\text { a incubadora for efetivamente entrar em ação seja criada a necessidade de manualizar também isso". }\end{array}$ \\
\hline
\end{tabular}

Fonte: Dados da Pesquisa dos autores deste artigo

A partir da análise do Quadro 3 verifica-se que, das cinco incubadoras estudadas, apenas duas possuem alguma parametrização sobre a maturidade dos produtos e serviços incubados para a inserção ao mercado. Tal fato demonstra que há a necessidade de elaboração ou adaptação de metodologias para que as incubadoras possam fornecer suporte à contento aos empreendimentos incubados para que estes não corram o risco de inserirem produtos sem o devido preparo.

Quando se trata da atuação da incubadora quanto ao estudo da maturidade da disponibilização da tecnologia para o mercado, se fala principalmente da etapa que Atrasas et al. (2003) chamaram de fase de maturação, que seria a saída da empresa da incubadora.

\section{Metodologias de Negociação, Valoração e TRL dos Produtos Incubados}

Nesse item, foi verificado junto às incubadoras se estas possuíam metodologias de negociação, valoração (Valuation) e estudo da maturidade das tecnologias desenvolvidas. Tal questionamento vem ao encontro do pensamento de Lee et al. (2010), que entendem que vários fatores são importantes em um processo de transferência de tecnologia, entre eles, o bom relacionamento comprador-fornecedor, item sempre presente nas atividades de negociação $e$ valoração dos produtos. 
Assim, segue o Quadro 4 em que detalha as respostas das incubadoras relacionadas ao seguinte questionamento: A incubadora possui alguma metodologia de negociação, valoração, estudo de maturidade tecnológica (TRL) dos produtos e serviços incubados? Se sim, qual?

Quadro 4 - Métodos de Negociação, Valoração e TRL das Incubadoras

\begin{tabular}{|c|c|}
\hline \multicolumn{2}{|r|}{ As INCUBADORAS POSSUEM MÉTOdOS NEgOCIAÇÃO, VALORAÇÃo E TRL? } \\
\hline 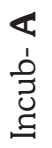 & $\begin{array}{l}\text { "Estudo do mercado, por meio do Modelo de Negócio a ser desenvolvido. } \\
\text { Esse estudo é feito tanto pela equipe da incubadora, quanto pelos docentes } \\
\text { que estão acompanhando o negócio e também pelos incubados". }\end{array}$ \\
\hline 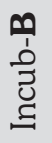 & $\begin{array}{l}\text { "Não há metodologia desenvolvida no momento. Mas contamos muito com a } \\
\text { experiência tanto de docentes quanto dos parceiros da agência de inovação que nos } \\
\text { dão o suporte tanto com relação à transferência quanto com a parte de PI". }\end{array}$ \\
\hline 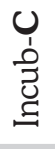 & $\begin{array}{l}\text { "A Incubadora não possui nenhuma metodologia de negociação ou valoração dos produtos das startups } \\
\text { incubadas. É uma atividade da Startup. Não há previsão ou intenção de atuarmos nessa questão". }\end{array}$ \\
\hline 早 & $\begin{array}{l}\text { "Não temos. Estamos a procura de parceiros externos com expertise para a } \\
\text { elaboração desses estudos para darmos o suporte aos nossos incubados". }\end{array}$ \\
\hline ب̂. & $\begin{array}{l}\text { "Atualmente ainda não há trabalho nesse sentido. Mas como estamos em implantação, vamos verificar } \\
\text { quais instrumentos já poderíamos construir para iniciarmos da forma mais organizada possível". }\end{array}$ \\
\hline
\end{tabular}

Fonte: Dados da Pesquisa dos autores deste artigo

Verifica-se que das cinco incubadoras, quatro não possuem nenhuma metodologia de negociação, valoração ou maturidade tecnológica (TRL). Tal questão demonstra a incipiência dos instrumentos principais no processo de transferência tecnológica, que seriam a negociação com possíveis compradores, a precificação ou a aplicação do devido valor à determinada tecnologia e o estudo da maturidade de determinada tecnologia para disponibilização para o mercado.

Cysne (2005), por exemplo, afirma que o ambiente empresarial está cada vez mais agressivo, e a competitividade por parte das empresas é questão sine qua non neste mercado global. Já Avellar (2005) entende que o processo de avaliação de uma nova tecnologia é complexo, porque há dificuldades de se mensurar especialmente os impactos econômicos da implantação da mesma. Observou-se, que a negociação e valoração de intangíveis é atualmente um dos principais gargalos das incubadoras amazônicas, motivados entre outros pelas limitações de pessoal especializado.

\section{Considerações Finais}

O presente estudo objetivou analisar como as incubadoras de empresas da Amazônia atuam para apoiar o processo de transferência das tecnologias dos empreendimentos incubados, tendo como fonte primária da pesquisa os sites das ICTs e os links destinados à unidade de incubação, além da utilização de formulários e entrevistas com os gestores das incubadoras. 
Apesar de um universo de apenas cinco incubadoras respondentes, das vinte e três contatadas, o que se entende como um fator de limitação da presente pesquisa, pôde-se, no entanto, tomar alguns resultados do estudo. Quanto a análise dos sites institucionais das incubadoras, por exemplo, em especial com relação às informações relativas às estratégias de transferência tecnológica, pôde-se observar que de maneira geral as incubadoras (e também os NITs) pouco têm descrito como funciona este processo. Entre os motivos é que, como observou-se, quando se trata de TT, a atuação da maioria das incubadoras analisadas tem se resumido ao encaminhamento dos casos para os NITs das ICTs.

Mesmo cientes de que as incubadoras estão entre os vários mecanismos de transferência tecnológica e de que os NITs são os responsáveis pela gestão da política de inovação nas ICTs do país, entende-se que no rol do processo de incubação a comunicação tecnológica deve ser um pilar importante para o desenvolvimento e fortalecimento mercadológico, e que nesta questão as incubadoras, mesmo não sendo o ator principal na função de gestão da inovação, poderiam atuar de maneira mais "agressiva" fazendo com que empresas incubadas, graduadas, spin-offs ou não, aumentassem o rol de produtos e serviços transferidos para a sociedade. Tal entendimento corrobora com um dos fatores críticos citados por Atrasas (2005), em que afirma ser o fator humano (fornecedor e receptor da tecnologia) fundamental no processo de TT. Ressalte-se, ainda, o que afirmam Closs e Ferreira (2012), quando tratam da comunicação tecnológica entre as atribuições das incubadoras no apoio ao processo de transferência tecnológica.

Outro ponto a ser tratado enquanto resultado deste estudo é no que trata da incipiência detectada em relação aos instrumentos de negociação, valoração e estudo de prontidão tecnológica (TRL) por parte das incubadoras analisadas. Entende-se, pois que estas estratégias devem fazer parte do know how das incubadoras amazônicas, para o eficiente apoio quanto à transferência de produtos e serviços para o setor produtivo, e que seja tanto por meio da cessão quanto da concessão ou licenciamento tecnológico.

Um ponto relevante identificado no estudo, é o uso de parcerias no processo de TT, enquanto solução para a carência de recursos humanos e financeiros das ICTs amazônicas. Cita-se, a iniciativa da incubadora "C" que realiza parceria com uma agência de inovação do sudeste do país (Agência de Inovação da UFRJ), o que entende-se ser uma um benchmarking para as demais incubadoras que ainda não utilizam esta estratégia.

Quanto a possíveis propostas de estudos futuros, vislumbra-se duas em especial: a análise de como incubadoras de outros centros do país e até do exterior atuam no processo do estímulo à transferência tecnológica e quanto aos modelos de gestão de incubadoras. Tal fato se levanta em virtude de que na presente pesquisa verificou-se que há experiências de incubadoras e NITs atuando juntas sob a mesma unidade gestora, nos casos em estudo, enquanto membros de agências de inovação, e experiências de incubadoras vinculadas à outras unidades.

\section{Referências}

ALMEIDA, C. C. O. F. Metodologia científica e inovação tecnológica: desafios e possibilidades. Brasília, DF: Instituto Federal de Educação, Ciência e Tecnologia de Brasília, 2012.

ANPROTEC. Estudo, Análise e Proposições sobre as Incubadoras de Empresas no Brasil: Relatório Técnico. Associação Nacional de Entidades Promotoras de Empreendimentos Inovadores. Ministério da Ciência, Tecnologia e Inovação. Brasília: ANPROTEC, 2012. 
ANPROTEC. Estudos de impacto econômico no segmento de Incubadoras de Empresas do Brasil. Disponível em: http://www.anprotec.org.br/Relata/18072016\%20Estugo_ANPROTEC_ V6.pdf. Acesso em: 21 nov. 2018.

AVELLAR, A. P. M. Metodologia de avaliação de políticas tecnológicas: uma resenha a partir de experiências internacionais. Santiago, Chile: CEPAL, 2005.

ATRASAS, A. L.; GOMES, G. C.; ELOI, M. A.; CHOAIARY, R. Incubação de empresas modelo Embrapa. Embrapa Transferência de Tecnologia, 2003.

AUTM. The Association of University Technology Managers. 2013. Disponível em: http://www. autm.net/Home.htm. Acesso em: 7 abr. 2013.

BOZEMAN, B. Technology transfer and public policy: a review of research and theory. Research Policy, v. 29, n. 4, p. 627-655, 2000.

BRASIL. Lei n. 13.243, de 11 de janeiro de 2016. Dispõe sobre estímulos ao desenvolvimento científico, à pesquisa, à capacitação científica e tecnológica e à inovação e altera a Lei n. 10.973, de 2 de dezembro de 2004, a Lei n. 6.815, de 19 de agosto de 1980, a Lei n. 8.666, de 21 de junho de 1993, a Lei n. 12.462, de 4 de agosto de 2011, a Lei n. 8.745, de 9 de dezembro de 1993, a Lei n. 8.958, de 20 de dezembro de 1994, a Lei n. 8.010, de 29 de março de 1990, a Lei n. 8.032, de 12 de abril de 1990, e a Lei n. 12.772, de 28 de dezembro de 2012, nos termos da Emenda Constitucional no 85, de 26 de fevereiro de 2015. Diário Oficial da República Federativa do Brasil, Brasília, DF, 12 jan. 2016. Disponível em: http://www.fundep.ufmg.br/wp-content/ uploads/2018/09/Livro_marco_regulatorio_em_ciencia_tecnologia_e_inovacao.pdf. Acesso em: 8 jul. 2019.

CLOSS, L. Q.; FERREIRA, G. C. A transferência de tecnologia universidade-empresa no contexto brasileiro: uma revisão de estudos científicos publicados entre os anos 2005 e 2009. Gest. Prod., São Carlos, v. 19, n. 2, p. 419-432, 2012.

COSTA, L. B.; TORKOMIAN, A. L. V. Um Estudo Exploratório sobre um Novo Tipo de Empreendimento: os Spin-offs Acadêmicos. RAC, Curitiba, v. 12, n. 2, p. 395-427, abr.-jun. 2008.

CYSNE, F. P. Transferência de tecnologia entre universidade e a indústria. Revista Eletrônica de Biblioteconomia e Ciência da Informação, [S.l.], n. 20, 2005.

GARDIM, N. et al. Portal corporativo como ferramenta de geração de conhecimento e de mobilização para a inovação: Um esforço real no Brasil. In: Anais [...] XIV Congreso LatinoIberoamericano de Gestión Tecnológica - ALTEC 2011, 2011, Lima - Peru.

GIL, A. C. Como elaborar projetos de pesquisa. 5. ed. São Paulo: Atlas, 2008.

GOMES, G. C.; ATRASAS, A. L. Diretrizes para transferência de tecnologia: modelo de incubação de Empresas. Brasília, DF: Embrapa Informação Tecnológica, 2005. 36p. (Embrapa Informação Tecnológica. Documentos, 2).

IACONO, A.; ALMEIDA, C. A. S.; NAGANO, M. S. Gestão da Inovação em empresas nascentes de base tecnológica: Evidências em uma incubadora de empresas no Brasil. Inerciencia, [S.I.], v. 39, n. 5, maio 2014.

IBGE - Instituto Brasileiro de Geografia e Estatística. Vegetação. [2014]. Disponível em: https://www.ibge.gov.br/geociencias/informacoes-ambientais/vegetacao/15819-amazonia -legal. html? =\&t=o-que-e. Acesso em: 15 jul. 2019. 
KELLI, A.; METS, T.; JONSSON, L. Management of Intellectual Property Rights in academia: The Estonian and Swedish perspectives. International Journal of Technology Management \& Sustainable Development, [S.I.], v. 13, n. 3, p. 219-236, Sept. 2014. ISSN: 14742748.

KIPPER, L. M. et al. Gestão por processos: comparação e análise entre metodologias para implantação da gestão orientada a processos e seus principais conceitos. Tecno-Lógica, [S.l.], v. 15, n. 2, p. 89-99, 2011.

\section{LARGENT, M. C. A Probabilistic Risk Management Based Process for Planning and}

Management of Technology Development. Thesis for the Degree Doctor of Philosophy in Aerospace Engineering. Georgia Institute of Technology, 2003.

LAVE, M. E. L.; SILVA, M. C. M.; SOUSA, K. A. Geração de negócios: um modelo sugerido para a incubadora de negócios em um centro de biotecnologia na Amazônia. In: SIMPÓSIO DE ADMINISTRAÇÃO DA PRODUÇÃO, LOGÍSTICA E OPERAÇÕES INTERNACIONAIS. São Paulo, 2010. Anais eletrônicos. São Paulo: Editora FGV/EAESP, 2010. Disponível em: http:/www.simpoi. fgvsp.br/arquivo/2010/artigos/E2010_T00134_PCN43296.pdf. Acesso em: 7 fev. 2013.

LEE, J., WIN, H. N. Technology transfer between university research centers and industry in Singapore. Technovation, [S.1.], v. 24, n. 5, p. 433-442. 2004.

MACEDO, M. B. F.; BASSALO, G. M. Comunicação e integração entre os associados da Rede Amazônica de Incubadoras de Empresas - RAMI. In: TINHOLO, Josealdo; PIRES, Sheila Oliveira (org.). Caminhos para o sucesso em incubadoras e parques tecnológicos: um guia de boas práticas. Brasília: ANPROTEC \& SEBRAE, 2005. p. 79-80.

MONTEIRO, G. F. As boas práticas da comunicação como ferramenta para promover a cultura empreendedora e a inovação na Fundação PaqTcPB. In: TINHOLO, Josealdo; PIRES, Sheila Oliveira (org.). Caminhos para o sucesso em incubadoras e parques tecnológicos: um guia de boas práticas. Brasília: ANPROTEC \& SEBRAE, 2005. p. 28-30.

NATIONAL BUSINESS INCUBATION ASSOCIATION - NBIA. What is business incubation? [2008]. Disponível em: https://inbia.org/. Acessado em: 20 nov. 2018.

OLIVEIRA, M. L. G., MENDONÇA, C. M. C.; Ambientes Promotores de Inovação: Caracterização do Suporte Oferecido Pelas Incubadoras de Empresas dos Institutos Federais da Amazônia. In: MENDONÇA, Claudio Márcio Campos; CHAVES, Daniel (org.). Inovação na Amazônia. Debates Sobre Tecnologia, Desenvolvimento e Empreendedorismo. 1. ed. Macapá: Editora da Universidade Federal do Amapá, 2018. v. 1, p. 1-464.

PASKINN, H. S.; SIZA, M. P. P.; GARNICA, L. A. O mapa do empreendedorismo da amazônia: características das incubadoras e perfil empresarial de base tecnológica. Revista Eletrônica Ciência e Desenvolvimento, [S.l.], v. 1, n. 1, ago. 2015. Disponível em: http://www.periodicos.ufam.edu.br/ ciencia_e_desenvolvimento/article/view/937. Acesso em: 28 jul. 2019.

SURVEYGIZMO. Using word clouds to present your qualitative data. Sandy McKee. [2012]. Disponível em: https://www.surveygizmo.com/survey-blog/what-you-need-to-know-when-usingwordclouds-to-present-your-qualitative-data. Acesso em: 28 jul. 2019.

TEIXEIRA, E. P.; CASTRO, M. S. F. Contribuição das incubadoras no processo de transferência de conhecimento e tecnologia das universidades às empresas. In: XVI CONGRESSO LATINOIBEROAMERICANO DE GESTÃo DA TECNOLOGIA, 2015, Porto Alegre, RS. Anais [...]. Porto Alegre, 2015. Disponível em: http://altec2015.nitec.co/altec/papers/541.pdf. Acesso em: 26 jul. 2019. 


\section{Sobre os Autores}

\section{Márcio Luís Góes de Oliveira}

E-mail: marcio.oliveira@ifap.edu.br MBA em Gestão Empresarial.

Endereço profissional: IFAP - Instituto Federal do Amapá, BR 210, Km 3, s/n, Brasil Novo, Macapá, AP. CEP: 68909-398.

\section{Cirilo Simões Filho}

E-mail: cirilosimoesfilho@gmail.com

Especialização em Agentes de Inovação e Difusão Tecnológica.

Endereço profissional: CEAP - Centro de Ensino Superior do Amapá, Rodovia Duca Serra, Via 17, 350, Alvorada, Macapá, AP. CEP: 68906-720.

\section{Cláudio Márcio Campos de Mendonça}

E-mail:cmarcio@gmail.com

Doutorado em Administração.

Endereço profissional: UNIFAP - Universidade Federal do Amapá, Rod. Juscelino Kubitschek, km 02, Jardim Marco Zero, Macapá, AP. CEP: 68903-419.

\section{Walter Teixeira Lima Júnior}

E-mail: walterteixeiralimajunior@gmail.com

Doutorado em Ciências da Comunicação.

Endereço profissional: UNIFESP - Universidade Federal de São Paulo, Rua Sena Madureira, n. 1.500, Vila Clementino, São Paulo, SP. CEP: 04021-001. 